\title{
Spatial and temporal dynamics of the use of fire in the Atlantic Forest of Sergipe
}

\author{
Daniel Brondani Ilha ${ }^{1 *}$
}

${ }^{1}$ Brazilian Institute of Environment and Renewable Natural Resources Aracaju, Brazil
*e-mail: $\underline{\text { daniel.ilha@ibama.gov.br }}$

ABSTRACT - The monitoring of fire hotspots is an important tool for environmental management and evaluation, allowing us to understand the dynamics and trends of fire use. In Brazil, INPE detects hotspots by images generated by optical sensors, capable of capturing electromagnetic radiation in the thermal average range of $4 \mu \mathrm{m}$. The aim of this study is to analyze the spatial and temporal distribution of the hotspots detected in the years 2016 and 2017 by the VIIRS sensor (NPP-375 platform) in the area covered by the Atlantic Forest biome in the state of Sergipe, based on vector data from the Atlas of Forest Remnants of 2016 produced by SOS Atlantic Forest, as well as in areas destined to Rural Settlements managed by Incra. The vectors of the hotspots were obtained in the Fire Database of CPTEC/INPE, while the vectors of rural settlements were obtained in of Incra and the National System of the Rural Environmental Registry. The best capacity for refinement and detection of hotspots motivated the choice of platform NPP-375. From the intersection of vector layers at GIS, the incidence of 2,187 hotspots was identified in the study area, of which only 260 are associated with phytophysionomys of the Atlantic Forest biome: Forest 186, Sandy coastal plain vegetation (Restinga) 61 and Mangrove 13. Of the 186 hotspots recorded in forest area, 17 focus on the Legal Reserve of Rural Settlements. The hotspots were detected with greater intensity in the dry season, however this condition is not only associated with moisture and the rainfall reduction, but also to the cycle of crops that use fire as a form of management, as is the case with sugarcane. It is noteworthy that the occurrence of 1,873 hotspots beds coincided with the peak of sugarcane harvesting in Sergipe that occurs between November and March. The state of Sergipe lacks government actions that promote alternative techniques to the use of fire in the harvesting of sugarcane, as well as preventive actions and fire fighting in Rural Settlements.

Keywords: burned area, hotspots, sugarcane 